\title{
THE MEASUREMENT OF A NOVEL CONCEPTUAL FRAMEWORK ENTITLED: "PROCESS EDUCATION: LEARNING TO LEARN" VIA AN EXPLICATIVE ENCYCLOPEDIA OF INNOVATIVE TRIOSTATISTICAL METHODS, MODELS, METRICS, AND STATISTICAL PROCEDURES
}

\author{
By \\ JAMES EDWARD OSLER II * \\ PHILLIPH MASILA MUTISYA ** \\ * Professor, School of Education, North Carolina Central University, USA. \\ ** Professor, Educational Technology Program, North Carolina Central University, USA. \\ Date Received: \\ Date Revised: \\ Date Accepted:
}

\section{ABSTRACT}

This paper is part two of the research paper entitled, "AMOVA" ["Accumulative Manifold Validation Analysis"]: An Advanced Statistical Methodology designed to measure and test the Validity, Reliability, and Overall Efficacy of Inquiry-Based Psychometric Instruments" published in the 2015 Journal of Educational Technology. In this narrative AMOVA is operationalized via successful "Process Education: Learning to Learn" (Or "PE: L2L"). PE: L2L experiences, whether taught in a camp, course or as professional development requires addressing specific principles, practices, scales, strategies, and concepts that are native to both "Process Education (PE)" and "Learning to Learn" (L2L). PE and L2L were once separate methodologies but are now combined here to create a novel, innovative, and comprehensive learning practice. This new learning model as an all-inclusive learning strategy uniquely unifies the implementation of $L 2 L$ experiences using the PE philosophy through the idea of "Transformational Education". Facilitating L2L through the lens of $P E$ requires the implementation and use of a preset of PE: $L 2 L$ practices and principles that are measureable via AMOVA. L2L has been implemented and researched in Europe and Process Education as a model has been implemented and its concepts have been tested and measured in the United States. This paper provides a unique cohesive perspective that incorporates the best of PE and the best of L2L to create "PE: L2L". PE: L2L is a novel conceptual framework that incorporates the principles, practices, scales, strategies, and concepts of both PE and L2L into a new measurable paradigm. In addition, three triostatistical models are presented in this text as ideal data analysis methods for the measurement of the new PE and L2L unification, they are: 1.) Tri-Squared Analysis (Osler, 2012); 2.) AMOVA (Os/er, 2015); and 3.) The Taxonomy of Process Education (Osler, 2015). The philosophical and theoretical foundational narrative in this paper is adapted from the results of successful PE "Learning to Learn Camps"; "Teaching Institutes"; and online PE professional development.

Keywords: Accumulative Manifold Validation Analysis (AMOVA), Conceptual Framework, Learning to Learn (L2L), Process Education: Learning to Learn (PE: L2L), Taxonomy of Process Education (PE), Tri-Squared Analysis, Tri-Squared Test, Triostatistics.

\section{INTRODUCTION}

Implementing Learning to Learn within the framework of Process Education is the operational rationale for this paper. The impact of this new and novel approach to learning has the ability to transform "Traditional Education" into a learning environment that promotes student "selfgrowth" through the "Process Education: Learning to Learn" experience. Process Education, "Learning to Learn", and "Process Education: Learning to Learn Experience" are each defined in detail to provide clarity 
on each of the practices and its inherent concepts, methods, and strategies as follows: 1.) Process Education: According to the "Academy of Process Educators" "Process Education" is defined in the following manner: "A performance-based philosophy of education which integrates many different educational theories, processes, and tools in emphasizing the continuous development of learning skills through the use of assessment principles in order to produce learner selfdevelopment" (Process Education, 2017); 2.) Learning to Learn: According to Rožman and Koren in their research work presented at the 2013 International Conference on Management, Knowledge, and Learning "Learning to Learn" (or " $L 2 L$ ") is defined as follows: "Learning to learn is the ability to pursue and persist in learning, to organise one's own learning, including through effective management of time and information, both individually and in groups. This competence includes awareness of one's learning process and needs, identifying available opportunities, and the ability to overcome obstacles in order to learn successfully. This competence means gaining, processing, and assimilating new knowledge and skills as well as seeking and making use of guidance. Learning to learn engages learners to build on prior learning and life experiences in order to use and apply knowledge and skills in a variety of contexts: at home, at work, in education and training. Motivation and confidence are crucial to an individual's competence" (European Communities, 2007, p. 8 in Rožman \& Koren, 2013); and 3.) "Process Education: Learning to Learn" Experience: The arena of "Process Education: Learning to Learn" is the use of Learning to Learn through the lens of Process Education concepts, models, measures, and strategies. As such, "Process Education: Learning to Learn" or "PE: L2L" is best defined through a constructs model that highlights the exactly how L2L is used in PE between the two areas. A Compendium of Triostatistical Methods, Models, and Metrics for PE: L2L follows in Table 1.

\section{The Current List Triostatistical Measures and Metrics}

Table 1 is an exhaustive list of currently published Triostatistical measures in use in investigative inquiry (noting that the vast majority of these tests and metrics

\begin{tabular}{|c|c|}
\hline Number & Name of Measure \\
\hline 1 & Tri-Symmetrical Tests; \\
\hline 2 & The Trimetric Tri-Squared Test; \\
\hline 3 & Tri-Squared Mean Cross Comparative Analysis; \\
\hline 4 & Trivariant Analysis; \\
\hline 5 & TRINOVA ["Trichotomous Nomographical Variance"]; \\
\hline 6 & TRICOVA ["Trichotomous Covariance"]; \\
\hline 7 & $\begin{array}{l}\text { MULTICOVA ["Multiple Trichotomous Coefficient of } \\
\text { Variation Analysis"]; }\end{array}$ \\
\hline 8 & Trichotomous Progression Analysis; \\
\hline 9 & $\begin{array}{l}\text { TRICOM ["Trichotomous Comparative Oneness of } \\
\text { Measurement"]; }\end{array}$ \\
\hline 10 & Tri-Center Analysis; \\
\hline 11 & $\begin{array}{l}\text { Tri-Squared Meta-Analysis (which can be applied to verify, } \\
\text { validate, and make viable non-Triostatistical measures using } \\
\text { Triostatistics inquiry methodologies); }\end{array}$ \\
\hline 12 & Tri-Factor Analysis; \\
\hline 13 & $\begin{array}{l}\text { AMOVA ["Accumulative Manifold Validation Analysis"] (which } \\
\text { can generally be applied to non-Triostatistical measures); }\end{array}$ \\
\hline 14 & TVA ["Trichotomous Visual Analytics"]; \\
\hline 15 & Tri-CFA ["Trichotomous Confirmatory Data Analysis"]; \\
\hline 16 & Tri-EDA ["Trichotomous Exploratory Data Analysis"]; \\
\hline 17 & Tri-BFA ["Trichotomous Bayes Factor Analysis"]; \\
\hline 18 & Tri-Triple I ["Trichotomous Invariant Instrument Inequality"]; \\
\hline 19 & Trichotomous Mixed Methods Analysis; \\
\hline 20 & Trioinformatics; \\
\hline 21 & Trichotomous-Cubed Test ["Tri3"]; \\
\hline 22 & TRIMOD ["Trichotomous-Cubic Parametric Model"]; \\
\hline 23 & MULTRICOR ["Multiple Trichotomous Correlation" Analysis] \\
\hline 24 & $\begin{array}{l}\text { TEM ["Triangular Equation Modelling"] (which explains } \\
\text { trichotomous research architecture that can be generally be } \\
\text { applied to any initial non-Triostatistical measure); and }\end{array}$ \\
\hline 25 & $\begin{array}{l}\text { Tri- } \Sigma \text { Test ["The Triple-Sigma Test"] (similar to "Tri-Squared Meta } \\
\text {-Analysis" in that it can be applied to verify, validate, and } \\
\text { make viable non-Triostatistical measures using Triostatistics } \\
\text { methodologies); }\end{array}$ \\
\hline 26 & IMI ["Intentionality Measurement Instrumentation"]; \\
\hline 27 & $\begin{array}{l}\text { Visualus Visioneering Volumetrics (for Tri-coordinate } \\
\text { Instructional Systems Design Problem-Solving - which } \\
\text { creates the foundational Isometric Cuboid model for } \\
\text { all Triostatistical Tri-Cubed Tests based upon the "Total } \\
\text { Transitive Theorem of Visualus"; }\end{array}$ \\
\hline 28 & $\begin{array}{l}\text { Trigma Cubed (for the specific testing of the efficacy of a } \\
\text { Visualus problem-solving solution using the "Total Transitive } \\
\text { Trigma" multiplicative product Isometric Cuboid solution } \\
\text { formula and Isometric Cuboid model); }\end{array}$ \\
\hline 29 & $\begin{array}{l}\text { Trimensional Analysis (also referred to as "Tri-Coordinate } \\
\text { Analysis") (for the specific testing of the efficacy of an } \\
\text { educational instructional intervention/solution using a } \\
\text { summative Visualus Isometric Cuboid solution formula } \\
\text { and Isometric Cuboid model); and }\end{array}$ \\
\hline 30 & $\begin{array}{l}\text { Tri-Power Analysis ["The Tri-Power Test as a Trifold Analytic" a } \\
\text { multiple in-depth triostatistical trichotomous examination } \\
\text { on a particular criterion]. }\end{array}$ \\
\hline
\end{tabular}

Table 1. An Exhaustive List of Triostatistics Research Methodologies and Tests

can be used beyond Triostatistical research inquiry, however, a few are descriptively highlighted in the list due to their specific use with extraneous research methods that extend their use beyond the stringencies of trichotomy):

Summary of Table 1: Table 1 details Triostatistics by name 
as an organized labelling method that can be easily accessed and rapidly referred to for a quick reference. Table 2 provides detailed definitions of all of the metrics and measures that are listed in Table 1.

\section{Identifying Triostat Research Applicability via a Tabular Triostatistics Encyclopedia}

Summary of Table 2: Table 2 details Triostatistics from an identity and usability format that specifically provides

\begin{tabular}{|c|c|c|c|c|}
\hline $\begin{array}{l}\text { Research } \\
\text { Stage }\end{array}$ & Name of Measure & Definition by Research Use and Utility in Investigative Inquiry & $\begin{array}{l}\text { Universal } \\
\text { Utility }\end{array}$ & $\begin{array}{l}\text { Requires } \\
\text { Trichotomy }\end{array}$ \\
\hline Primary & The Tri-Squared Test & Trichotomous Transformation of Qualitative into Quantitative Data; & Yes & Yes \\
\hline Post Hoc & Tri-Symmetrical Tests & $\begin{array}{l}\text { In-Depth Analysis of statistically significant Tri-Squared Test Data to } \\
\text { Determine Association; }\end{array}$ & No & Yes \\
\hline Post Hoc & The Trimetric Tri-Squared Test & $\begin{array}{l}\text { Uses the mathematical "Del" symbol and Matrix Algebra to determine } \\
\text { the Construct Validity of statistically significant Tri-Squared Test instruments; }\end{array}$ & No & Yes \\
\hline Post Hoc & $\begin{array}{l}\text { Tri-Squared Mean Cross Comparative } \\
\text { Analysis }\end{array}$ & $\begin{array}{l}\text { An in-depth study of means extracted from an statistically significant } \\
\text { Tri-Squared Test; }\end{array}$ & No & Yes \\
\hline Post Hoc & Trivariant Analysis & $\begin{array}{l}\text { Validates statistically significant Tri-Squared Test research outcomes via } \\
\text { Trichotomous Repeated Measures as advanced Tri-Analytic inquiry; }\end{array}$ & No & Yes \\
\hline Post Hoc & Trichotomous Nomographical Variance & $\begin{array}{l}\text { An advanced statistical measure that is designed to check the validity } \\
\text { and reliability of a statistically significant Tri-Squared Test; }\end{array}$ & No & Yes \\
\hline Post Hoc & Trichotomous Covariance & $\begin{array}{l}\text { An advanced measure the overall size of the movement (or change) } \\
\text { between inputted and outputted statistically significant Tri-Squared Test } \\
\text { variables; }\end{array}$ & No & Yes \\
\hline Post Hoc & $\begin{array}{l}\text { Multiple Trichotomous Coefficient of } \\
\text { Variation Analysis }\end{array}$ & $\begin{array}{l}\text { An advanced measure of the multiple means, variances, standard } \\
\text { deviations, coefficient of variations, variables, and assays of a statistically } \\
\text { significant Tri-Squared Test; }\end{array}$ & No & Yes \\
\hline Post Hoc & Trichotomous Progression Analysis & $\begin{array}{l}\text { Used to construct the Trichotomous Progression Line to determine the } \\
\text { growth or decline of statistically significant Tri-Squared Test Results; }\end{array}$ & No & Yes \\
\hline Primary & $\begin{array}{l}\text { Trichotomous Comparative Oneness of } \\
\text { Measurement }\end{array}$ & $\begin{array}{l}\text { A procedure for the internal testing of the outcomes of the Tri-Squared } \\
\text { Test for single subject and single case study designs; }\end{array}$ & Yes & Yes \\
\hline Post Hoc & Tri-Center Analysis & $\begin{array}{l}\text { A measure of Trichotomous Central Tendency for the Parametric } \\
\text { (Gaussian or Normal Curve) Analysis of a statistically significant } \\
\text { Tri-Squared Test Results; }\end{array}$ & Yes & Yes \\
\hline Post Hoc & Tri-Squared Meta-Analysis & Use of the Tri-Squared Test to analyze existing data; & Yes & Yes \\
\hline Post Hoc & Tri-Factor Analysis & $\begin{array}{l}\text { An in-depth way of investigating overall effectiveness statistically } \\
\text { significant Tri-Squared Test based on a rectilinear Tri-Factor model; }\end{array}$ & Yes & Yes \\
\hline Primary & Accumulative Manifold Validation Analysis & $\begin{array}{l}\text { A statistical methodology designed to test any psychometric } \\
\text { instrument; }\end{array}$ & Yes & No \\
\hline Post Hoc & Trichotomous Visual Analytics & The Graphical Representation of the Outcomes of the Tri-Squared Test; & Yes & Yes \\
\hline Primary & Trichotomous Confirmatory Data Analysis & The Primary Analysis Methodology of the Tri-Squared Test; & Yes & Yes \\
\hline Post Hoc & Trichotomous Exploratory Data Analysis & Visual Representation of the Outcomes of the Tri-Squared Test; & Yes & Yes \\
\hline Post Hoc & Trichotomous Bayes Factor Analysis & $\begin{array}{l}\text { Alternative Post Hoc Bayesian probability test to confirm Confirmatory } \\
\text { Data Analysis and Exploratory Data Analyses of Tri-Squared Test outcomes; }\end{array}$ & No & Yes \\
\hline Primary & Trichotomous Invariant Instrument Inequality & $\begin{array}{l}\text { The Design metric for trichotomous Triple-l Researcher Designed } \\
\text { Tools for Research; }\end{array}$ & Yes & Yes \\
\hline Primary & Trichotomous Mixed Methods Analysis & $\begin{array}{l}\text { A mixed methods model that uses the Tri-Squared Test to validate } \\
\text { research outcomes from other measures; }\end{array}$ & Yes & Yes \\
\hline Primary & Trioinformatics & $\begin{array}{l}\text { The Creation of Trichotomous Models to Define trichotomous and } \\
\text { Tri-Squared Test Research; }\end{array}$ & Yes & Yes \\
\hline Primary & Trichotomous-Cubed Test & $\begin{array}{l}\text { A trichotomous Meta-Analysis model that uses a tri-coordinate design } \\
\text { based on Visualus calculation analytic model to analyze existing data; }\end{array}$ & Yes & Yes \\
\hline Post Hoc & Trichotomous-Cubic Parametric Model & $\begin{array}{l}\text { An advanced Visualus-based tri-coordinate cubic model, measure, } \\
\text { and methodology of external and internal validity designed to more } \\
\text { accurately detail the outcomes of a statistically significant Tri-Squared } \\
\text { Test; }\end{array}$ & No & Yes \\
\hline Post Hoc & Multiple Trichotomous Correlation & $\begin{array}{l}\text { An advanced measure that is designed to check the validity and } \\
\text { reliability of a statistically significant Tri-Squared Test using multiple } \\
\text { internal trichotomous correlation; }\end{array}$ & No & Yes \\
\hline Primary & Triangular Equation Modelling & $\begin{array}{l}\text { A right triangular model that explains the trichotomous research } \\
\text { design methodology; }\end{array}$ & Yes & Yes \\
\hline Primary & The Triple-Sigma Test & $\begin{array}{l}\text { Analysis of Multiple Tri-Squared Tests Delivered at Different } \\
\text { Times; }\end{array}$ & Yes & Yes \\
\hline
\end{tabular}




\begin{tabular}{|c|c|c|c|c|}
\hline Primary & Intentionality Measurement Instrumentation & $\begin{array}{l}\text { A scalar measurement model and associated instrumentation that } \\
\text { is designed to measure the intent and/or purpose of a given Event, } \\
\text { Experience, Interaction, Assessment, and/or Outcome }\end{array}$ & Yes & No \\
\hline Primary & Visualus Visioneering Volumetrics & $\begin{array}{l}\text { A the assessment model of the comprehensive and cumulative } \\
\text { mathematical field of study called "Visualus" that uses systemic and } \\
\text { sequential Instructional Systems Design as an in-depth problem-solving } \\
\text { methodology (it also creates the foundational "Isometric Cuboid Model" } \\
\text { for all Triostatistical Tri-Cubed Tests based upon the mathematical "Total } \\
\text { Transitive Theorem of Visualus" also referred to as the "Essential Theorem } \\
\text { of Visualus"; }\end{array}$ & Yes & No \\
\hline Primary & Trigma Cubed & $\begin{array}{l}\text { The assessment methodology for the specific testing of the efficacy of a } \\
\text { Visualus problem-solving solution using the "Total Transitive Trigma" in a } \\
\text { detailed and in-depth multiplicative product formula that is grounded } \\
\text { in the Visualus Isometric Cuboid model); }\end{array}$ & Yes & No \\
\hline Primary & Trimensional Analysis & $\begin{array}{l}\text { Also referred to as "Tri-Coordinate Analysis" is based upon the term } \\
\text { "Trimensional" defined as the portmanteau of the terms "Tri-Coordinate" } \\
\text { (meaning "3 Coordinates") + "One Dimension" = "Trimensional", is a } \\
\text { methodology for the specific testing of the efficacy of an educational } \\
\text { instructional intervention/solution using a summative Visualus Isometric } \\
\text { Cuboid solution formula and associated within the framework of the } \\
\text { Visualus Isometric Cuboid model); and }\end{array}$ & Yes & No \\
\hline Primary & The Tri-Power Analysis & $\begin{array}{l}\text { A rigorously complex, meticulous, and detailed Analysis Method that } \\
\text { uniquely combines four Triostatistics: 1.) The Tri-Cubed Test;2.) The Tri- } \\
\text { Squared Test; 3.)The Tri-Sigma Test; and lastly 4.) Tri-Meta Analysis to } \\
\text { determine the viability, validity, and verifiability of an inquiry, intervention, } \\
\text { or a solution based on its efficacy [effectiveness], essentiality [condition], } \\
\text { and exactness [functionality]. }\end{array}$ & Yes & Yes \\
\hline
\end{tabular}

Table 2. The Detailed Definitive Triostatistics Identity and Usability Table

detailed definitions of all of the metrics and measures that are associated with primary and post hoc trichotomous research and analytics. Table 3 provides a construct model of PE and L2L with the unifying utilization model and methodology diagram displayed between the two.

Summary of Table 3: Table 3 exhibits, "The PE: L2L Constructs Model". This model was created by the authors and refined via feedback by members of the "Academy of Process Educators". The Table is organized with a list of 10 PE outcomes and experiences on the far right with a definitive set of triangular models in the midsection that connect PE with $\mathrm{L} 2 \mathrm{~L}$ and on the far left are the $3 \mathrm{~L} 2 \mathrm{~L}$ definitions that accurately define curriculum as reproduction, production, and transformation respectively.

\section{Support for Process Education and Learning to Learn}

Process Education (Or "PE") has been in some form or fashion on the educational landscape for approximately 26 years. Support for its concepts and ideology have gained widespread backing. Evidence of this can be seen in the 2016 research article entitled, "25 Years of Process Education: Commemorating 25 Years of Scholarship in Process Education and the $10^{\text {th }}$ Anniversary of the Academy of Process Educators" by Apple et al.

\begin{tabular}{|c|c|c|}
\hline $\begin{array}{l}\text { Process Education (PE) } \\
\text { (Apple, Ellis, and Hintze, } \\
2016 \text { ) }\end{array}$ & $\begin{array}{l}\text { Defining Learning to } \\
\text { Learn (L2L) Practices } \\
\text { Utilized in Process } \\
\text { Education (PE) in } \\
\text { the Process of PE: } \\
\text { L2L Experiences }\end{array}$ & $\begin{array}{l}\text { Learning to Learn (L2L) } \\
\text { (Kelly, } 1999 \text { as cited by } \\
\text { Priestley \& Humes, 2010) }\end{array}$ \\
\hline $\begin{array}{l}\text { 1. Methodologies; } \\
\text { 2. Learning Process } \\
\text { Methodology; } \\
\text { 3. Reflection/Meta- } \\
\text { Cognition; }\end{array}$ & & $\begin{array}{l}\text { The curriculum as } \\
\text { content, and education } \\
\text { as transmission } \\
\text { (reproduction); }\end{array}$ \\
\hline $\begin{array}{l}\text { 4. Self-Assessment; } \\
\text { 5. Performance Criteria; } \\
\text { 6. Self-Growth/Growth } \\
\text { Mindset; }\end{array}$ & & $\begin{array}{l}\text { The curriculum as } \\
\text { product, and education } \\
\text { as instrumental } \\
\text { (production); and }\end{array}$ \\
\hline $\begin{array}{l}\text { 7. Accelerator Model; } \\
\text { 8. Performance Measures; } \\
\text { 9. Performance Model; } \\
\text { and } \\
\text { 10. Classification of } \\
\text { Learning Skills }\end{array}$ & & $\begin{array}{l}\text { The curriculum as } \\
\text { process, and education } \\
\text { as development } \\
\text { (transformation). }\end{array}$ \\
\hline
\end{tabular}

Table 3. The "Process Education: Learning to Learn" Constructs Model

(2016). They go on to state the following in support for PE in "25 Years of Process Education": "As of this writing, Process Education (PE) has been around for 25 years. If it were a person, we would expect to see it making its own way in 
the world - standing on its own two feet, as it were - in contexts that no longer necessarily involve those who brought it into being. And so it is. The life and growth of this philosophical approach to education consists of various stages of growth, important milestones, and noteworthy contributions and achievements. And as it has grown and evolved in clarity, organization and utility, its impact upon higher education has only increased. Over the last 25 years more than 50,000 faculty, staff, and administrators have been exposed to the principles and practices of Process Education, largely through professional development and scholarly efforts. While there is no way to accurately tally those who have adopted even some of what Process Education offers, a diverse community of serious practitioners has evolved over time. The genesis of this group began with a series of conferences entitled Problem Solving Across the Curriculum (1990-1996) and the community grew between 1999 and 2002 and became more coherent as a result of a major scholarship effort (The Faculty Guidebook: 2003-2007), eventually culminating in the Academy of Process Educators (2007 to present). This group is not definitive; there are Process Educators who are not members of the Academy and, thanks to the "stickiness" of many of the ideas in Process Education - that they have import, attraction, and utility that are obvious to many educators - there are surely individuals who could be termed "Process Educators" who may well have never heard the term Process Education" (Apple etal., 2016).

Support for "Learning to Learn" (or "L2L") is presented in the 2013 Oxford Review of Education research article by Pirriea and Thoutenhoofd entitled, "Learning to Learn in the European Reference Framework for Lifelong Learning" (Pirriea \& Thoutenhoofd, 2013) that states the following: "The hallmark of L2L is the development of a fluid sociality rather than the promotion of fluent task-oriented behaviour. Moreover, we believe that the embodied, situated, affective, and creative dimensions of $L 2 L$ have previously been subordinated to the cognitive dimension, and have thus received insufficient attention. This is partly due to the fact that for the last 50 years human capital theory has served as a powerful steering mechanism across the European political landscape (Gillies, 201 1, p. 240). This article is intended to redress this imbalance, and more importantly to begin to clarify the epistemological basis of L2L. This will entail wresting this concept from a narrow identification with self-regulated learning and meta-cognition" (Flavell, 1976 \& 1979).

4. The Process Education: Learning to Learn (PE: L2L) Conceptual Framework

There are critical components of implementing "Process Education: Learning to Learn" as dynamic and interactive learning experiences that foster and promote "selfgrowth". This process can best be illustrated in the form of a concept map. Concept mapping by nature inherently displays all of the various aspects of an ideology or procedure. Jabareen (2009) in his work "Building a Conceptual Framework: Philosophy, Definitions, and Procedure" defines a conceptual framework as "a network, or "a plane," of interlinked concepts that together provide a comprehensive understanding of a phenomenon or phenomena. The concepts that constitute a conceptual framework support one another, articulate their respective phenomena, and establish a framework-specific philosophy. Conceptual frameworks possess ontological, epistemological, and methodological assumptions, and each concept within a conceptual framework plays an ontological or epistemological role. The ontological assumptions relate to knowledge of the "way things are", "the nature of reality", "real" existence, and "real" action. The epistemological assumptions relate to "how things really are" and "how things really work" in an assumed reality (p. 108). The methodological assumptions relate to the process of building the conceptual framework and assessing what it can tell us about the "real" world" (Jabareen, 2009).

Jabareen originally stated in his 2008-09 publication in the International Journal of Qualitative Methods entitled, "Building a Conceptual Framework: Philosophy, Definitions, and Procedure" the following: "(with support from a variety of conceptual framework researchers) that the main features of conceptual frameworks are as follows: 1.) A conceptual framework is not merely a 
collection of concepts but, rather, a construct in which each concept plays an integral role. According to Miles and Huberman (1994), a conceptual framework "lays out the key factors, constructs, or variables, and presumes relationships among them" (p. 440); 2.) A conceptual framework provides not a causal/analytical setting but, rather, an interpretative approach to social reality (Jabareen, 2009); 3.) Rather than offering a theoretical explanation, as do quantitative models, conceptual frameworks provide understanding (Jabareen, 2009); 4.) A conceptual framework provides not knowledge of "hard facts" but, rather, "soft interpretation of intentions" (Levering, 2002, p. 38); 5.) Conceptual frameworks are indeterminist in nature and therefore do not enable us to predict an outcome. To support this notion Levering (2002) has suggested that "the idea that human behavior can be explained and predicted is roughly based on the concept of external factors being caught in an accidental cohesion, and the idea that human actions can be understood, but not predicted, is based on the concept of freedom" (p. 38); 6.) Conceptual frameworks can be developed and constructed through a process of qualitative analysis (Jabareen, 2009); and lastly; 7.) The sources of data consist of many discipline-oriented theories that become the empirical data of the conceptual framework analysis. Although conceptual framework analysis generates theories or conceptual frameworks from multidisciplinary bodies of knowledge, metasynthesis, a systematic synthesis of findings across qualitative studies, seeks to generate new interpretations for which there is a consensus within a particular field of study (Jensen, \& Allen, 1996; Nelson, 2006; Sandelowski, Docherty, \& Emden, 1997). In "metasynthesis", which is both hermeneutic and comparative in nature, the researcher aims to expand our interpretation (Sandelowski, 1993) beyond existing qualitative studies from the same discipline (Paterson et al., 2009). Moreover, whereas conceptual analysis aims to produce concepts, metasynthesis produces metaphors, ideas, concepts, and more. Usually, metasynthesis initially selects studies and then identifies key metaphors, ideas, concepts, and relations in each one (Nelson, 2006; see also Campbell et al., 2003; Noblit \& Hare, 1988; Jabareen, 2009).

\section{Effective Implementation of the Process Education Conceptual Framework}

To facilitate effective learning experiences that are transformational in approach based on the way the curriculum is designed, how it is applied, and measured requires an intentional engaged process (Mastery of the curriculum is critical for implementation). The process also involves developing the learning and growth environment that is transformational, affective, and effective in engaging the learner to a newly developed personal life vision. The facilitator has to create a public desire for a consistent measurement approach with clear performance criteria that challenges the learners to keep improving their performance. It also requires the facilitator to formally integrate methodologies.

There is a distinction that is important in facilitating learning that is transformational in order to produce designed learning outcomes. One of the aspects that is ignored is the experiential learning which involves active learning and training of the mind to think in a certain way that engages the learner to think and act, that are attributes to adult learning experience need in fulfilling personal urgency and growing self-efficacy (noncognitive leadership efficacy "Experiential learning" (Kolb, 2014) that also contributes to developing awareness on self-concept (Lynch \& Chaves, 1975; Lynch, Norem-Hebeisem \& Gergen, 1981). In the last 20 years (Apple et al., 2016) have developed a L2L curriculum through the lens of Process Education that has been transforming the way higher education is done for over 25 years by focusing on growth and development. The PE: L2L curriculum development process has identified specific aspects that are effective in demonstrating change and transformational learning environment that facilitators or learners have to apply in order to produce desired measurable learning outcomes in teaching and learning (PE: L2L Curriculum). However, there are eight institutional cultural and policy critical barriers that have been identified through teaching institutes and learning to learn camps by Pacific Crest that have been found to present challenges in the efforts of 
transforming teaching and learning. Table 4 that follows includes a list of those barriers that have been found to be critical in facilitating culture of success in educational intuitions that must be addressed in order to achieve the desired transformational and high quality learning environment and leadership (based upon the 14 aspects-Reds to Green presented in as "Figure 8 Scales used to describe red, yellow, and green performance in each aspect", Beyerlein, Burke \& Hintze, 2012).

Summary of Table 4: Table 4 illustrates, "Critical Cultural Barriers in Implementing L2L". The Table is organized with a list of barriers on the right with adjacent definitions to the left that explain in detail why the barriers are significant. Educational research and its contributions in terms of value can address all of the critical Cultural Barriers that can impede effective PE: L2L implementation. There is a virtual plethora of research (both continuing and ongoing) that can and will allow the facilitator of PE: L2L to ground their work in empirical evidence that supports the most positive aspects of PE: L2L. However, the facilitator must be aware of the notion of superiority complex which can and will defeat all of their efforts in PE: L2L. This phenomenon is better characterized by the Dunning-Kruger effect: "The Dunning-Kruger effect is a cognitive bias wherein unskilled individuals suffer from illusory superiority, mistakenly assessing their ability to be much higher than is accurate. This bias is attributed to a metacognitive inability of the unskilled to recognize their ineptitude. Conversely, highly skilled individuals tend to underestimate their relative competence, erroneously assuming that tasks which are easy for them are also easy for others. As David Dunning and Justin Kruger of Cornell University conclude: "The miscalibration of the incompetent stems from an error about the self, whereas the miscalibration of the highly competent stems from an error about others." (Kruger \& Dunning, 1999). A profile of PE: L2L defeats and counters the Dunning-Kruger effect the next section covers this topic in detail.

\section{A Profile of PE: L2L Facilitator's Responsibilities [an In- Depth Profile]}

Learning to learn experience requires the instructor as "PE: L2L Facilitator" to have specific set of instructional efficacy skills that informs practice and identifies the initial "self-growth learning conditions" to students. This set of PE: L2L skills includes: 1.) How to help students identify their own learning risk factors; 2.) How to develop student's ability to identify their own learning outcomes; and 3.) Development of student growth goals in the learning environment as an ongoing process. As such, a PE: L2L Facilitator of (for example) a "PE: Learning to Learn Camp" or a "specified course that adheres to PE: L2L principles" must engage students through a PE: L2L pre-assessment process. It is this process which helps the students to do the following: A.) Identify their own individual's personal learning risk factors; B.) Obtain their own learning and growth goals; and C.) Build connectivity in at least three learning-related dimensions to aid them in building instructional-setting rapport. Subsequently, the PE: L2L

\begin{tabular}{|c|c|}
\hline Barriers & Why are They Significant Barriers \\
\hline 1. Fixed Mind; & Close to $100 \%$ of incoming students lean strongly to a fixed mindset vs. growth mindset \\
\hline 2. Self-evaluation; & Individuals are unaware of the power of self-assessment \\
\hline 3. Not owning student failures; & $\begin{array}{l}\text { Most faculty are unwilling to fully accept the responsibility for facilitating success for all } \\
\text { their students }\end{array}$ \\
\hline 4. Disdain for use of methodologies; & $\begin{array}{l}\text { Few faculty believe in the generalization of process knowledge as a model and believe } \\
\text { that it dumbs down the expertise }\end{array}$ \\
\hline 6. Non-transformational learning culture (Red to green culture); & $\begin{array}{l}\text { Change and growth are impacted by the educational culture that is established and } \\
\text { unfortunately the current culture is non-growth culture }\end{array}$ \\
\hline 7. Limited facilitators tool set; and & $\begin{array}{l}\text { Facilitating a Learning to Learn Camp/Course requires a strong set of skills in facilitation, } \\
\text { assessment, mentoring (constructive interventions) }\end{array}$ \\
\hline 8. Minimal believe in the value of Educational research. & $\begin{array}{l}\text { Most faculty teach the way they were taught and rarely use research to inform teaching } \\
\text { (common practice is try and error approach) }\end{array}$ \\
\hline
\end{tabular}


Facilitator creates a "focused-on-self-growth" learning environment that holistically generates "a cultural desire for the transformational learning". Accordingly, the Facilitator must know which PE: L2L process, tool, technique, or strategy is effective in driving both the learner and the learning environment towards "dedicated constructive intervention" designed to produce growth and a high-quality learning environment. It is also understood that the Facilitator has to have a clear understanding of the specified curriculum and its design, sequencing, and synergistic qualities that will uniquely allow students to leverage (in timely manner) opportunities to consistently advance and promote selfgrowth.

Further additional essential knowledge areas that are needed by the PE: L2L Facilitator include using the guiding principles of Process Education that are generally adhered to in one's daily professional, family, and personal life (these are also considered to be "empowerment processes"). Indeed the Facilitator of PE: L2L must know how to elevate his/her own practices in all the key PE processes in order to implement the planned curriculum through PE: L2L effectively. This knowledge thereby aids the Facilitator in modeling "quality performance" in each of the following PE transmission of information processes: a.) facilitation; b.) assessment; c.) mentoring; d.) collaborating; e.) evaluating; f.) problem solving; g.) leadership; and h.) self-growth. Knowledge in each of the aforementioned $8 \mathrm{PE}$ information processes also requires the facilitator to have a very clear distinction between the two operative PE parameters: 1.) Assessment [or "the arena of measurement"]; and 2.) Evaluation [or "the arena of judgment"]. The PE: L2L Facilitator thereby models their personal experiences and curriculum expertise in both of these operational arenas with their students. Thus, an effective PE: L2L Facilitator is also an engaging "PE: L2L Mentor" who then guides performance to advance assessment (via the practice) for the specific purposes of providing empowerment in the learning environment to enhance overall selfconcept and in this manner elevate self-growth throughout the learning process. There are 10 primary characteristics that a PE: L2L Facilitator as a PE: L2L Mentor must have to both promote and sustain the process of self-growth in the learning environment they are

- Have a very strong belief in each learner's potential for success, convey this clearly to each student consistently, and share personal experiences and results of previous students' successes;

- Are very caring individuals who connect with their students, build rapport, and express this caring in a productive and meaningful way by putting student's interests first.

- Have emotional toughness (strong affective skill set) that allows them to carry out tough love-holding their students accountable for their commitment and performance given very difficult personal factors and circumstances.

- Consistently self-assess their own performance, learn and grow from these performances so their future PE: L2L performance continually improves and thusly they are much more successful for a greater percentage of the students under their care.

- Continuously model a set of productive professional behaviors that students will and can emulate and use "a language of success" that produces positive reinforcement, encourages, and thereby creates an environment for productive growth.

- Mentor the growth of their student's learning skills by letting learners do for themselves, learn by discovery, and provide constructive interventions when learners struggle with specific learning skills.

- Put in extra effort to reach out to students who are having difficulties and are about to withdraw from the process and bring them back successfully.

- Produce an enriching and engaging learning environment where there is a high expectation, a strong shared commitment, adventurous risk taking, inspiration and encouragement, temporary failure, quality assessment, reflection and documentation of growth, and steadily increasing challenges.

- The facilitator also takes the responsibility for the performance and success of each learning team 
and member within the learning community by preparing facilitation plans for each activity and effectively implements a focus on higher levels of learning through critical thinking and having students teach each other through communication skills to learn intra-group and inter-group communication. Facilitation with improvisation must be used when necessary. This process then motivates via counsel, creates collaboration, sustains professional development, and gives quality feedback to grow the performance of each learning team.

- The Facilitator diagnoses key individual learning issues and in collaboration with each student come up with customized growth plan that addresses these learning issues. The Facilitator also challenges each student daily to help keep improving their performance by assessing work products, assessing the reflective and assessment produced by the students, and assessing students self-assessments.

\section{Measurement of Process Education: Learning to Learn} for Assessment and Continuous Growth

Measurement is essential to Process Education: Learning to Learn. It is very evident in the assessment methodology, process, and procedures. There are two primary and very valuable tools that are essential to the measurement of PE: L2L and its outcomes. They are a vital part of the science of "Triostatistics" which is the measurement field adjacent to PE:L2L. The Triostatistics assessment measurement procedures that have direct application to PE:L2L are Tri-Squared Analysis and Accumulative Manifold Validation Analysis or "AMOVA". They are defined as follows: 1.) Triostatistics: The science and field of Triostatistics is comprehensively defined as follows-"The word "Triostatistics" is a portmanteau of the terms: "Triochotomous" and "Statistics"; that can also be referred to as "Triostat", "Advanced Trichotomy", or "The Science of Trichotomy". More definitively Triostatistics is descriptively defined as, "a branch of the science statistics that is the specific application of statistical methods, techniques, and strategies to a wide range of topics that are concerned with primary and post hoc measurements, the mathematics of trichotomy, innovative statistical measures, and in many cases the outcomes of the Tri-Squared Test" (Osler, 2014). At the heart of this statistical discipline is the application of the mathematical "Law of Trichotomy".

The science of Triostatistics encompasses the design of Tri-Squared experiments, especially in education and social behavioral settings. However, the utility and flexibility of Triostat as a body statistical metrics allows it to be applied to a variety of sciences (through the use and application of the mathematical "Law of Trichotomy") (Osler, 2014); 2.) Tri-Squared Analysis: The Total Transformative Trichotomous-Squared Test provides a methodology for the transformation of the outcomes from qualitative research into measurable quantitative values that are used to test the validity of hypotheses. The advantage of this research procedure is that it is a comprehensive holistic testing methodology that is designed to be static way of holistically measuring categorical variables directly applicable to educational and social behavioral environments where the established methods of pure experimental designs are easily violated.

The unchanging base of the Tri-Squared Test is the $3 \times 3$ Table based on Trichotomous Categorical Variables and Trichotomous Outcome Variables. The emphasis the three distinctive variables provide a thorough rigorous robustness to the test that yields enough outcomes to determine if differences truly exist in the environment in which the research takes place. As it states in the $|G|$ Global book entitled, "Handbook of Research on Educational Technology Integration and Active Learning" (Keengwe, 2015): "The Tri-Squared research procedure uses an innovative series of mathematical formulae that do the following as a comprehensive whole: (1) Convert qualitative data into quantitative data; (2) Analyze inputted trichotomous qualitative outcomes; (3) Transform inputted trichotomous qualitative outcomes into outputted quantitative outcomes; and (4) Create a standalone distribution for the analysis possible outcomes and to establish an effective-research effect size and sample size with an associated alpha level to test the validity of an established research hypothesis (Keengwe, 
2015; Mutisya, Osler, Bitting \& Rotich 2014; Osler, 2012, 2013, 2014, \& 2015); and 3.) AMOVA which was first defined by Osler in 2015 in the research publication entitled "AMOVA ["Accumulative Manifold Validation Analysis"]: An Advanced Statistical Methodology Designed to Measure and Test the Validity, Reliability, and Overall Efficacy of Inquiry-Based Psychometric Instruments", as follows - "AMOVA: Accumulative Manifold Validation Analysis ["AMOVA"] is a specialized statistical methodology designed to test the internal and external validity of uniquely designed psychometric instruments. AMOVA uses a mathematically specialized form of inquiry that is an arithmetic form of natural mean optimization that is parallel to the discipline of linear stochastic modelling. AMOVA is an in-depth statistical procedure for the internal testing of research instruments based on the metrics from a novel taxonomy based on and grounded in "Process Education". This new taxonomy is referred to as the "Taxonomy of Process Education" (or "TPE") (Osler, 2015)".

Osler further states in the 2015 research article "AMOVA" published in the 2015 the following: "The TPE is based off of the Process Education (or "PE") four-level measures designed to measure self-growth. The Taxonomy of Process Education (TPE) is based off of the Process
Education [PE] (Pacific Crest, 2015) four-level measures designed to measure self-growth. The PE four levels in particular are viewed as sequential stages (as levels and/or phases) of professional development. The four-level measures are also constructed to build towards the highest level of content knowledge or subject matter expertise and are: 1.) Emerging (the lowest level); 2.) Developing (the next stage that arises from Emerging and illustrates a higher level of self-growth and authenticallybased learning); followed by 3.) Proficient (the next level and second highest level of growth displaying the ability to adequately implement the task and/or skillset); and lastly followed by 4.) Accomplished (the highest level demonstrating mastery of the topic, concept, task, skillset, and/or requirement). The PE four levels in particular are viewed as sequential stages (or phases) that through the TPE ideally measure "professional development" (Osler, 2015). Table 5 immediately follows and details the 0 through 4 metrics of TPE by providing a logical sequence of definitive categories, scalar characterizations, assigned weights, calculative outcomes, and data type descriptions (Osler, 2015).

Summary of Table 5: The defined in the Journal of Educational Technology (Osler, 2015) publication entitled, "AMOVA" stated the following that applies to

\begin{tabular}{|c|c|c|c|c|c|c|c|c|}
\hline $\begin{array}{l}\text { Repetitively } \\
\text { Assigned } \\
\text { Mathematical } \\
\text { Weight }\end{array}$ & $\begin{array}{c}\text { "Equal } \\
\text { to" }\end{array}$ & $\begin{array}{l}\text { Measurement } \\
\text { of Self-Growth } \\
\text { Scale }\end{array}$ & $\begin{array}{l}\text { "Identic } \\
\text { to" }\end{array}$ & $\begin{array}{l}\text { Repetitive Weight } \\
\text { Assignment Based } \\
\text { on the Taxonomy } \\
\text { of Process Education } \\
\text { Self-Growth }\end{array}$ & $\begin{array}{l}\text { "Identical } \\
\text { to" }\end{array}$ & $\begin{array}{c}\text { Taxonomy of Process } \\
\text { Education Self-Growth: } \\
\text { Weighted Accumulative } \\
\text { Outcome }\end{array}$ & $\begin{array}{c}\text { "Parallel } \\
\text { to" }\end{array}$ & $\begin{array}{l}\text { Mathematical } \\
\text { Measurement } \\
\text { Data Type } \\
\text { Scalar Level }\end{array}$ \\
\hline 0 & $=$ & Empty & $\leftrightarrow$ & None & $\equiv$ & Non-Existent & $\|$ & $\begin{array}{c}\text { Self-Growthin terms of } \\
\text { Learning is at the Vacant } \\
\text { Level = Void }\end{array}$ \\
\hline 1 & $=$ & Weak & $\leftrightarrow$ & Seldom & $\equiv$ & Emerging & 11 & $\begin{array}{l}\text { Self-Growthin terms of } \\
\text { Learning is at the Nominal } \\
\text { Level = Name Only }\end{array}$ \\
\hline 2 & $=$ & Mild & $\leftrightarrow$ & Occasionally & $\equiv$ & Developing & $\|$ & $\begin{array}{l}\text { Self-Growthin terms of } \\
\text { Learning is at the Ordinal } \\
\text { Level = Rank Only }\end{array}$ \\
\hline 3 & $=$ & Strong & $\leftrightarrow$ & Often & $\equiv$ & Proficient & $\|$ & $\begin{array}{l}\text { Self-Growthin terms of } \\
\text { Learning is at the Interval } \\
\text { Level = Equidistantor } \\
\text { Balanced in Area }\end{array}$ \\
\hline 4 & $=$ & Perfect & $\leftrightarrow$ & Consistently & $\equiv$ & Accomplished & | & $\begin{array}{l}\text { Self-Growthin terms of } \\
\text { Learning is at the Ratio } \\
\text { Level = Ideal from the } \\
\text { Source or Starting Point }\end{array}$ \\
\hline
\end{tabular}

Table 5. The AMOVA Measurement Comprehensive Continuum of Self-Growth Table 
Table 5: "The AMOVA Continuum of Self-Growth provided to displays the sequential (left to right) relationship between the instrument values for the purposes of validation. In this manner, the individual weighted outcomes have a multiple manifold applicable rubric that illustrates how scores were obtained, their relative value, and their expression in terms of the Taxonomy of Process Education in terms of Self-Growth. Table 6 highlights "The Accumulative Crosswise-Validation Analysis Table" (Osler, 2015). This Table expands the scope of AMOVA and measures learning by defining it through a self-growth categorization methodology. Through this categorization the "Taxonomy of Process Education" defines statistical data types as categories of learning that build upon one another that at the highest level illustrate that learning can be defined from a self-growth perspective. For example, as a maximum score of the integer " 4 " = "Perfectly Consistent Accomplished Ideal Learning from the Source" (that is at a Ratio Level and exemplifies a statistical "Ratio" data type). Table 6 illustrates, "The Statistical Accumulative CrosswiseValidation Analysis Table for the Accumulative Manifold Validation Analysis" (Osler, 2015).

Summary of Table 6: The Accumulative CrosswiseValidation Analysis Table as it was originally defined in the Journal of Educational Technology (Osler, 2015) entitled,
"AMOVA ["Accumulative Manifold Validation Analysis"], states the following: "It is designed to yield sequential (left to right) instrumentation validation outcomes similar to the critical values used in the one factor Analysis of Variance [ANOVA] F Test statistical critical values charts. The F Test chart is designed to analyze multiple group research design variance as the "spread of scores". Note: The AMOVA $m_{\text {value }}$ is mathematically equal to the "AMOVA Cluster Axiom for Manifold Consistency". This is represented by arithmetic definition in the following manner: $\operatorname{psy}_{[[]]}=[n / m]=m_{\text {value }}=[\bar{m}]$. Where, 1.) $\operatorname{psy}_{[[i]}=$ The psychometric research instrument; 2.) [-] = Concentration on the quotient of...; 3.) $n=$ Total number of "psychometric research instrument items"; and 4.) m $=$ Total number of research categories (indicated by the term "m-fold" = "Manifold"). This is also indicative of the number of "psychometric research instrument items contained within manifolds" (Osler, 2015). Figure 1 presents, "The Primary Model of the Taxonomy of Process Education in Terms of Self-Growth" that further defines and displays the aforementioned concepts as a model for PE: L2L measurement.

Summary of Figure 1: The Accumulative Manifold Validation Analysis (AMOVA) Figure is the "Taxonomy of Process Education in Terms of Self-Growth". It is designed to illustrate the sequential hierarchal (from bottom to top)

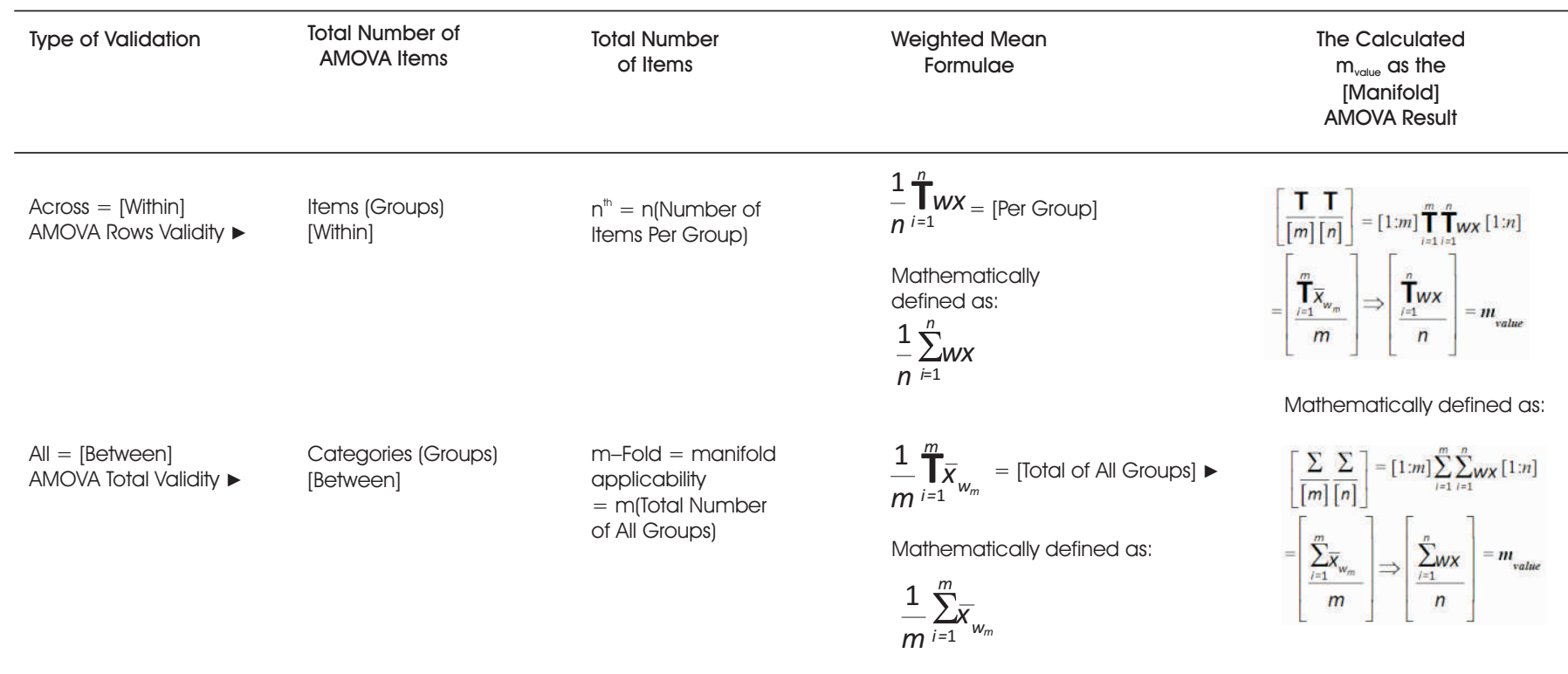




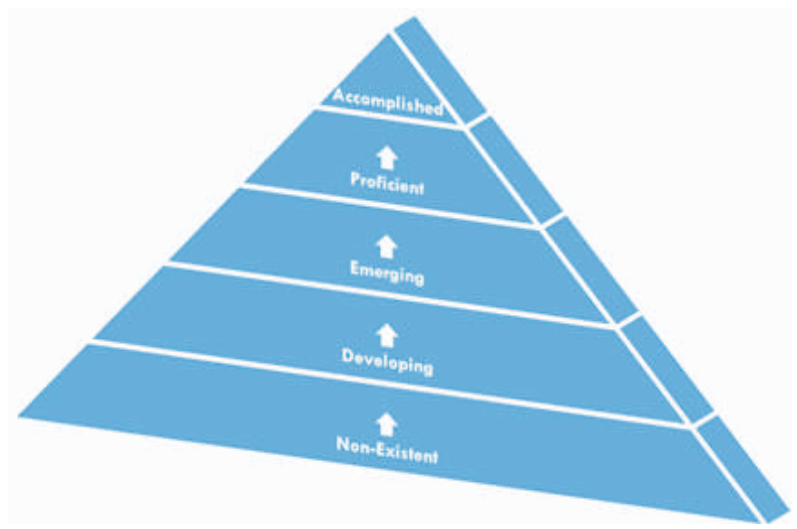

Figure 1. The Primary Model of the Taxonomy of Process Education in Terms of Self-Growth as Used to Measure All Types of Learning as Pure Forms of Professional Development

steps that one matriculates through from "No Experience" (i.e. "Non-Existent") to a maximized "Accomplished" Level indicating the penultimate level of achievement of "Professional Development". This particular taxonomy has universal applicability. The terms and associated values can be used to assess growth, disposition, content mastery, level of expertise, value of particular items, analysis of skill sets, the power relative to performance, the building of a specific set of measurement data (as in the course design "4A Metric" from Techtonics) the creation of implicit goals and objectives, and the amount of assigned value to a particular criterion. The quantitative numerical equivalent of these "indices" or "indicators" can be found in Table 5 which displays the holistic "Taxonomy of Process Education: Learning to Learn Continuum Measurement Rubric" specifically for the Itemization of Accumulative Crosswise-Validation Analysis for the purposes of research instrumentation psychometric analysis. Figures 2, 3, and 4 follow and presents, "The Explicative Model of the Repetitive Weight Assignment Based on the Taxonomy of Process Education in Terms of Self-Growth" (Osler, 2015) in a sequence of mathematical combined and singular mathematical floor and ceiling function triangular models that are Figures 2, 3, and 4 respectively.

Summary of Sequential Figures 2, 3, and 4: As stated in the Journal of Educational Technology (Osler, 2015) entitled, "AMOVA ["Accumulative Manifold Validation Analysis"]: An Advanced Statistical Methodology Designed to Measure

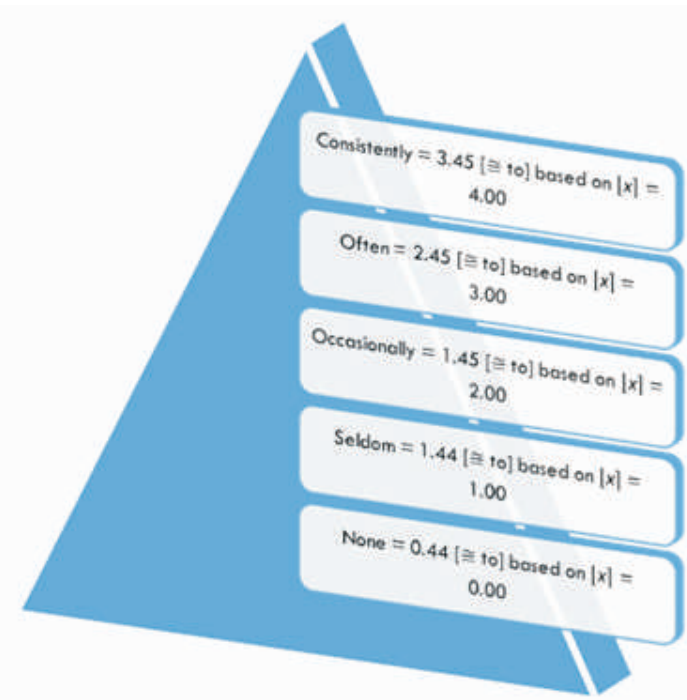

Mathematically this literally means the following:

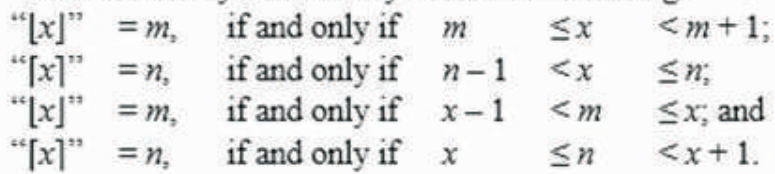

Figure 2. The Combined Function of the Explicative Model of the Repetitive Weight Assignment Based on the Taxonomy of Process Education in Terms of Self-Growth as Used to Measure Instrument Item Efficacy

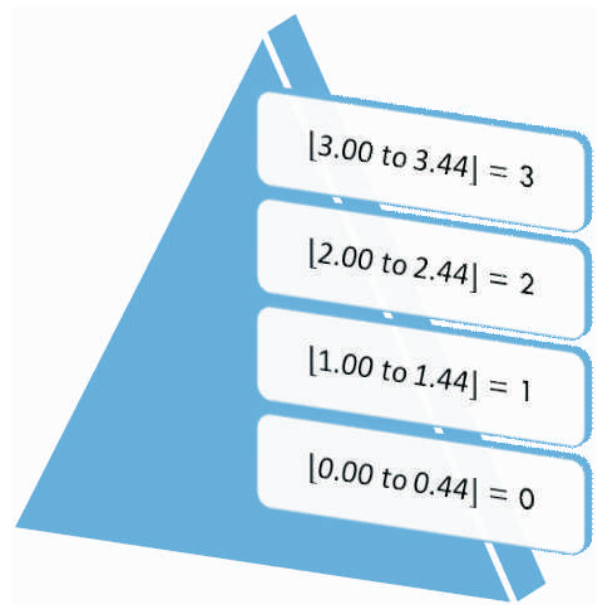

Figure 3. The Floor Function of the Explicative Model of the Repetitive Weight Assignment Based on the Taxonomy of Process Education in Terms of Self-Growth as Used to Measure Instrument Item Efficacy

and Test the Validity, Reliability, and Overall Efficacy of Inquiry-Based Psychometric Instruments" the following description most accurately describes the models (in particular Figure 2 which was illustrated in the original published article) as follows:

"The above Accumulative Manifold Validation Analysis 


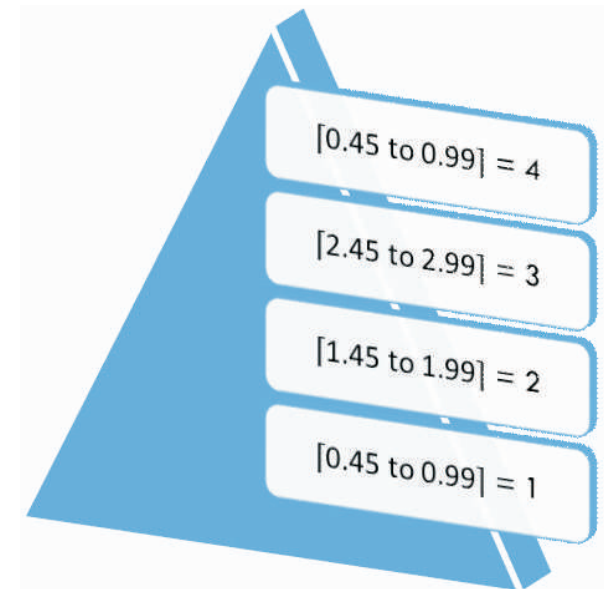

Figure 4. The Ceiling Function of the Explicative Model of the Repetitive Weight Assignment Based on the Taxonomy of Process Education in Terms of Self-Growth as Used to Measure Instrument Item Efficacy

Figure 2 is designed to explain the aforementioned Figure 1 in terms of mathematical weighted outcome yield as a mathematical "Combined Floor and Ceiling Function". It is sequential (from bottom to top) in terms of Professional development and associated Self-Growth (Osler, 2015). The base has an overall outcome of "Never" (initially presented in the original Osler, 2015 publication) or "Nor" or "None" (as it appears here at the base of the Figure 2 model which is equivalent to a mathematical term of " 0.00 "). Built into Figure 2 is the weighted assessment of instrument item efficacy based around this triangular diagram is the mathematical rounding of values to the nearest whole number (using the nearest integer function for the floor and ceiling function values to determine outputted weights per research instrument categorical cluster, see Table 3). This provides the pure value needed to determine each individual group (or categorical) quantifiable value that will be eventually used to determine the overall instrument efficacy as an "Accumulative Manifold Validation Coefficient" (based on the above integers as the Taxonomy of Process Education" base numerical values). It is important to note that the diagram above is a continuation of the "Taxonomy of Process Education Model" developed from the Academy of Process Educators assessment methodologies and is specifically designed in deference to Table 2 (in terms of listed sequential titles and their associated mathematical weighted instrument item values) (Osler, 2015). It is also important to note the floor and ceiling values in the model from the AMOVA as "[x]" (representing the "Taxonomy of Process Education Combined Floor and Ceiling Functions" in Figure 2), "[x]" (representing the "Taxonomy of Process Education Floor Function" in Figure 3), and " $[x]$ " (representing the "Taxonomy of Process Education Ceiling Function" in Figure 4). Floor and Ceiling functions respectively mathematically define the rounding methodology used to reach the "whole number" or integer value by mathematical rounding that is the core of Taxonomy of Process Education" (Osler, 2015).

\section{Summary and Conclusion}

The use of advanced triostatistics such as AMOVA can very efficiently and effectively measure novel methodologies such as Process Education: Learn to Learn. PE: L2L (effectively in the landscape of education $\mathrm{K}-20+$ ) has the ability to transform all of education (in a multiplicity of sectors)-from the elementary classroom to the halls of higher education from the unique perspective of "learning as present, past, and future professional development". The conceptual framework, metrics, measurement, strategies, and "Taxonomy of PE: L2L" can not only shed light on innovation in academia, but it can also greatly aid in the producing the next generation of educators who will shape and formulate how education will impact learners right now and in the near future.

The implementation of the triostatistics measurement analytics presented in this narrative (AMOVA in particular) can greatly enhance the understanding of "education as a science" or the development of "eduscience" (Osler, 2013) as comprehensive field. The implications are great and truly expansive for the growth and sustainable future of academicians as leaders in the academy. It is these leaders who seek to address, "the challenges and social change that demands a reconceptualization of education as a process to emphasize entrepreneurship and leadership throughout the academy" (Osler \& Mutisya, 2013). The measurable contextual texture of this change in education begins with the paradigm shift brought on by the measurement of learning (via novel 
statistical measures such AMOVAl and the implementation of comprehensive learning models such as PE: L2L. The measurement of PE: L2L directly addresses "transformational change" by thereby providing an acceptable data analysis conceptual framework that is grounded in years of research and training from both Europe and the United States. The advent of the PE: L2L conceptual framework measurement methodology now provides PE with a researchable acumen of credentials and metrics that allows educational researchers to further interpret the in-depth and rich complexities of learner selfgrowth through the lens of self-concept. The wide spread use of measurable PE: L2L in this context creates a uniquely empowering and dynamically engaging learning methodology that has a professional development perspective that is both approachable and plausible. This ultimately will push the body of knowledge in education (and all of the related fields that it both nurtures and touches) into new and vast expanses of creative learning environments established through energetic innovation that is focused on proprietary student development, authentic professional development, and capacious self-growth.

\section{References}

[1]. Apple, D., Ellis, W., \& Hintze, D. (2016). 25 years of process education: Commemorating 25 years of scholarship in process education and the $10^{\text {th }}$ anniversary of the academy of process educators. International Journal of Process Education, 8 (1), 3-154.

[2]. Beyerlein, S., Burke, K., \& Hintze, D. (2012). Concept maps for linking aspects in the transformation of education. International Journal of Process Education, $4(1), 43-60$.

[3]. Campbell, R., Pound, P., Pope, C., Britten N., Pill, R., Morgan, M. (2003). Evaluating metaethnography: A synthesis of qualitative research on lay experiences of diabetes and diabetes care. Social science and Medicine, 56(4), 671-684.

[4]. Flavell, J. H. (1976). Metacognitive aspects of problem solving. In L. B. Resnick (Ed.), The Nature of Intelligence (pp. 231-236). Hillsdale, NJ: Erlbaum.
[5]. Flavell, J. H. (1979). Metacognition and cognitive monitoring: A new area of cognitive-developmental inquiry. American Psychologist, 34(10), 906-91 1.

[6]. Gillies, D. (2011). State education as high-yield investment: Human capital theory in European policy discourse. Journal of Pedagogy, 2(2), 224-245.

[7]. Jabareen, Y. (2009). Building a conceptual framework: Philosophy, definitions, and procedure. International Journal of Qualitative Methods, 8(4), 49-62.

[8]. Jensen, L. A., \& Allen, M. N. (1996). Metasynthesis of qualitative findings. Qualitative Health Research, 6(4), 553-560.

[9]. Kelly, A. V. (1999). Curriculum Theory and Practice $\left(4^{\text {th }}\right.$ Ed.). London, UK: Sage.

[10]. Keengwe, J. (2015). Handbook of research on educational technology integration and active learning. IG| Global.

[1 1]. Kolb, D. A. (2014). Experiential Learning: Experience as the Source of Learning and Development ( $2^{\text {nd }} E d$.). FT Press.

[12]. Kruger, J., \& Dunning, D. (1999). Unskilled and unaware of it: How difficulties in recognizing one's own incompetence lead to inflated self-assessments. Journal of Personality and Social Psychology, 77(6), $1121-1134$.

[13]. Levering, B. (2002). Concept analysis as empirical method. International Journal of Qualitative Methods, $1(1), 35-48$.

[14]. Lynch, M. D., \& Chaves, J. (1975). Do self concept tests test self concept? An evaluation of the validity of items on the piers harris and coopersmith measures.

[15]. Lynch, M. D., Norem-Hebeisem, A. A., \& Gergen, K. J. (1981). Self-concept: Advances in Theory and Research. Cambridge, MA: Ballinger.

[16]. Miles, M. B., \& Huberman, A. M. (1994). Qualitative Data Analysis: An Expanded Source Book (2 $2^{\text {nd }}$ Ed.). Newbury Park, CA: Sage.

[17]. Mutisya, P. M., Osler, J. E., Bitting, P. F., \& Rotich, J. P. (2014). The Need for a Conceptual Framework for Leadership and Shared Governance between Faculty and Administrators. The International Journal of Process 


\section{RESEARCH PAPERS}

Education, 6(1), 43-52.

[17]. Nelson A. M. (2006). A metasynthesis of qualitative breast feeding studies. Journal of Midwifery \& Women's Health, 51(2), e13-e20.

[18]. Noblit, G. W., \& Hare, R. W. (1988). MetaEthnography: Synthesizing Qualitative Studies. Newbury Park, CA: Sage.

[19]. Osler, J. E. (2012). Trichotomy-Squared - A Novel Mixed Methods Test and Research Procedure Designed to Analyze, Transform, and Compare Qualitative and Quantitative Data for Education Scientists who are Administrators, Practitioners, Teachers, and Technologists. i-manager's Journal on Mathematics, 1 (3), 23-32.

[20]. Osler, J. E. \& Mutisya, P. M. (2013). A Tri-Squared Analysis to Establish the Need for a Statistical Framework for K-20 Faculty as Academic Leaders. Special Edition: "Instructional Technique and Technologies". Creative Education (Special Issue on Instructional Technique and Technologies), 4(8), 12-18.

[21]. Osler, J. E. (2013b). The Psychological Efficacy of Education as a Science through Personal, Professional, and Contextual Inquiry of the Affective Learning Domain. i-manager's Journal on Educational Psychology, 6(4), 3641.

[22]. Osler, J. E. (2014). Triostatistics: The Application of Innovative In-Depth Advanced Post Hoc Statistical Metrics for the Assessment and Analysis of Statistically Significant Tri-Squared Test Outcomes. Kentucky Journal of Excellence in College Teaching and Learning, 12(3), 27-39.

[23]. Osler, J. E. (2015). AMOVA ["Accumulative Manifold
Validation Analysis"]: An Advanced Statistical Methodology Designed to Measure and Test the Validity, Reliability, and Overall Efficacy of Inquiry-Based Psychometric Instruments. i-manager's Journal of Educational Technology, 12(3), 37-47.

[24]. Paterson B., Dubouloz, C. J., Chevrier, J., Ashe, B., King, J., \& Moldoveanu, M. (2009). Conducting qualitative metasynthesis research: Insights from a metasynthesis project. International Journal of Qualitative Methods, 8(3), 22-33.

[25]. Pirriea, A., \& Thoutenhoofd, E. D. (2013). Learning to learn in the European Reference Framework for lifelong learning. Oxford Review of Education, 39(5), 609-626.

[26]. Priestley, M., \& Humes, W. (2010). The development of Scotland's curriculum for excellence: Amnesia and de' ja ` vu. Oxford Review of Education, 36(3), 345-361.

[27]. Process Education. (2017). Process Education Definition. Retrieved from http://www.process education.org/ijpe/2016/pathfinder/areas/PE.html

[28]. Rožman L., \& Koren, A. (2013). Learning to learn as a key competence and setting learning goals. Proceedings of the Management, Knowledge and Learning International Conference 2013, 19-21, Zadar, Croatia.

[29]. Sandelowski, M. (1993). Rigor or rigor mortis: The problem of rigor in qualitative research revisited. Advances in Nursing Science, 16(2), 1-8.

[30]. Sandelowski, M., Docherty, S., \& Emden, C. (1997). Qualitative metasynthesis: Issues and techniques. Research in Nursing \& Health, 20, 365-371. 
ABOUT THE AUTHORS

Dr. James Edward Osler II is currently working as a Professor in the School of Education at North Carolina Central University in USA. $\mathrm{He}$ is an artist, has been a K-12 teacher, is an active researcher, an innovative technologist, and is currently a faculty member in the School of Education (SOE) at North Carolina Central University (NCCU). Dr. Osler is also the author of many influential refereed Journal articles, Books, and papers on topics as diverse as: 1) "Applied Educational Science"; 2)"Inventive Instructional Design"; 3) "Empowering Neuromathematics Concepts"; 4) "Algorithmic Online Learning"; 5) "Innovative Statistical Methods"; 6) "Novel Fields of Learning"; 7) "Ideal Technology Engineering"; and 8) "Applied Nanobiotechnology". He is a licensed North Carolina (NC) Preacher, K-12 Art Educator, and Instructional Technology Specialist with a Technology Endorsement. Dr. Osler is also certified in digital literacy, research, and visual programming. He has served on multiple refereed journal review boards and has authored several graduate-level degree and certificate programs. North Carolina State University (NCSU) has recognized him as one of its 100 Most Influential Black Alumni. He has received three of the highest and most respected honors at NCCU: "The Employee Recognition Award for Outstanding Service"; "The University Award for Teaching Excellence", and the first "Chancellor's Award for Innovation". He is also the recent recipient of the 2017 IGI Global Outstanding Scholars Award; 2017 Registry in Marquis Who's Who, and the 2017 COGIC (Church of GOD in Christ) Black History Achievement Award. 52.

Dr. Philliph Masila Mutisya is a Professor in the Educational Technology Program at North Carolina Central University, USA. He received his Doctorate of Education in 1989 in Instructional Leadership with a Concentration in Curriculum Development in Multicultural and Bilingual Education from the University of Massachusetts at Amherst, Massachusetts. He also has a M.Ed. in International Education with a concentration in Training and Development in Non-formal Education also from UMASS Amherst, Massachusetts. For over 28 years in Academia, he has also specialized in Educational Leadership in Instructional Training and Development with further expertise in Education, Curriculum Development. His research areas, include Instructional Leadership and Curriculum Development-research capacity building in interdisciplinary Critical Pedagogy \& Social Change, and Cultural Identity. "The Need for a Conceptual Framework for Leadership and Shared Governance between Faculty and Administrators". International Journal of Process Education (IJPE), Volume 6 (Issue 1). He is certified in Problem Based Learning (PBL), Process Education which includes expertise in training and development in Competency Based Learning (CBL) and Process Oriented Guided Inquiry Learning (POGIL). 